\title{
Deprivation and variations in teenage conceptions and abortions in England
}

\author{
Jonathan Bradshaw, Naomi Finch, Jeremy N V Miles
}

\begin{abstract}
There are substantial variations between local authorities in the conception rate of teenagers and the proportion of these that end in abortion. This study builds two deprivation models that explain part of the variation in conceptions and abortions. It then identifies outliers, local authorities with teenage conception and abortion rates that are above or below those predicted by the model. It is suggested that the local authorities with lower than expected conceptions are the ones to look to when seeking to discover how to prevent teenage conceptions and those with higher than expected abortion rates may have abortion services that are more accessible. In general, spatial comparisons of conceptions and abortion should take into account variations in deprivation.
\end{abstract}

J Fam Plann Reprod Health Care 2005; 31(1): 15-19 (Accepted 19 October 2004)

\section{Key message points}

- Deprivation explains about three quarters of the area variation in teenage conceptions and abortions.

- Having controlled for deprivation it is possible to identify areas with much higher or lower conception and abortion rates than you would expect.

- It is these areas where lessons might be learned about the effectiveness of policies designed to reduce teenage births.

\section{Introduction}

The purpose of this study was to find explanations for the variations that exist in the teenage conception rate and the proportion of these conceptions that are aborted in 352 local authorities in England. By 'teenage' we mean age 15-17 years, and this is the definition used throughout the article. In 1997-1999, the teenage (i.e. 15-17 years) conception rates varied between 15 per 1000 in Uttlesford and 86 per 1000 in Southwark. The proportion of teenage conceptions, which ended in abortion, varied between $26 \%$ in Derwentside and 68\% in Kensington and Chelsea.

Understanding the reasons for these variations may help more successful policies to be developed in pursuit of the Government's strategy to halve the rate of conceptions among under-18-year-olds in England by 2010, to set a firmly downward trend in the conception rates for under16-year-olds by 2010 and to achieve a reduction in the risk of long-term social exclusion for teenage parents and their children.

We know that variations in the prevalence of loneparent families by local authority are associated with and can be explained by the socioeconomic characteristics of the area described by the census.1,2 Some work has

Social Policy Research Unit, University of York, York, UK Jonathan Bradshaw, DPhil, Professor of Social Policy Naomi Finch, MSc, Research Fellow

Health Sciences, University of York, York, UK Jeremy N V Miles, PhD, Lecturer in Biostatistics

Correspondence to: Professor Jonathan Bradshaw, Social Policy Research Unit, University of York, Heslington, York YO10 5DD, UK. E-mail: jrb1@york.ac.uk been done on area variations in teenage conceptions and abortions. Smith ${ }^{3}$ aimed to determine the extent to which the rate of teenage conceptions, abortions and maternities in Tayside varied in different parts of the region in relation to the prevailing socioeconomic conditions. Throughout the 11 years studied, Smith found that the rates were four to eight times higher in the most deprived postcode areas than in the most affluent. However, the socioeconomic difference in the rate of abortion was much less pronounced: in the most deprived areas one in four pregnancies ended in abortion compared to two in three in the most affluent areas. A study by Wood ${ }^{4}$ used the Office for National Statistics (ONS) area classification groups of District Health Authorities to look at age-specific conception rates in 1993 and changes between 1983 and 1993. Slogett and Joshi ${ }^{5}$ used the ONS Longitudinal Study in order to investigate the association between the level of social deprivation in electoral wards and various life events, one such event being teenage births. The unadjusted correlation between the deprivation indicators and teenage birth was steep and positive: the more deprived the area, the greater the chance of giving birth as a teenager. However, instead of merely finding the relationship between area deprivation and the various lifestyle outcomes, they also investigated how far the relationship with area deprivation (using the census indicators) actually reflected the personal or household characteristics of resident individuals. Using a simple model they found that personal household factors outweigh deprivation in areas of above-average deprivation, while the slope remains positive across less deprived wards. In other words, the area associations between deprivation and teenage pregnancy using a census-based indicator of area deprivation are largely, if not entirely, accounted for by the individual level measures of the same indicators. Clements et $a l .^{6}$ attempted to account for the variation in the teenage conception rates and conception outcomes between health districts and census wards in the former Wessex Regional Health Authority from 1991 to 1994 . This is a particularly useful study because it examines the relative importance not only of the socioeconomic and demographic correlates of teenage pregnancy and its outcomes but also of different types of family planning provision.

The Social Exclusion Unit produced a report entitled Teenage Pregnancy ${ }^{7}$ that investigated the reasons behind the high levels of teenage pregnancy with a view to producing an integrated strategy to cut rates of teenage parenthood. Within the report they demonstrated that the poorest areas in England have teenage conception and birth rates up to six times higher than the most affluent areas. They also found, however, that variation existed between areas that suffered from approximately equivalent deprivation. The variation in teenage conceptions could therefore not be solely due to deprivation. In addition, the report found that abortion rates are also heavily influenced by type of area: in the poorest areas, women tend to have fewer abortions and are more likely to disapprove of abortions

Griffiths and Kirby 8 used the revised 1999 ONS classification of local authorities to examine geographical variations in conceptions to women aged under 18 years. They found that the variation between local authorities was 


\section{ARTICLE}

much less marked than if using the countries and regions boundaries. Ingham et al. ${ }^{9}$ looked at the factors affecting the conception rate amongst under-16-year-olds in areas which show the highest increases and decreases over the period 1991-1997. They identified 20 Health Authorities in each category and collected data on these through interviews with key people. Relevant documentation was also scrutinised, including annual public health reports, descriptions and/or evaluation of any local initiatives, and so on. It was found that those areas with decreasing conception rates were more likely than those with increasing conception rates to have established a breadth of initiatives relating to sexual health matters. In a more recent study, Lee et al. ${ }^{10}$ found more deprived areas have both higher rates of teenage conceptions and lower rates of abortion. Young women's decisions about abortion depended more on the economic and social context of their lives than abstract moral views, and there were also associations (regardless of deprivation levels) between high proportions of abortion, more extensive local family planning provision, higher proportions of female general practitioners (GPs) and greater independent sector abortion provision.

\section{Explanations for area variation in conceptions and abortions}

There are four types of explanation for area variations in conceptions and abortions.

\section{Statistical artefact}

The ONS has published data on the number of teenage conceptions leading to maternity and to abortion in the female population aged 15-17 years for each of the 352 local authorities (District) in England (and Wales) for the periods 1994-1996 and 1997-1999.11 The postcode of the woman's address at the time of the maternity or abortion is used to determine the local authority she was living in at the time of conception. The data (denominators and/or numerators) may be recorded incorrectly or, perhaps as a result of small numbers, they are subject to large variations from period to period. However, taking 3 years' data should overcome the latter problem.

\section{Social deprivation}

We know from the earlier studies outlined above that teenage conceptions are associated with low income, unemployment and other forms of social deprivation.

\section{Sociocultural factors}

These are any characteristics of the teenagers and their environment that are independent of policy, for example, ethnicity.

\section{Policy}

The hypothesis is that having checked the reliability of the data, controlled for deprivation and investigated the possibility of variation being explained by other sociocultural factors, the most likely reasons for variation lie in the policies being pursued at a local level.

\section{Methods}

In this paper we built explanatory models using a multiple regression in order to explain variation in the conception rate and the abortion rate in the 352 local authorities in England for two time periods: 1994-1996 and 1997-1999. (NB. Multiple linear regression is a statistical method concerned with explaining or predicting the variability of a continuous dependent variable using information from two or more continuous independent variables.) All variables were entered into the analysis simultaneously. We also built explanatory models for a hierarchical regression to test whether our 'best' model in the earlier period predicted the change in conception/abortion rates in the later period. (NB. Hierarchical regression is used where there are one or more independent predictor variables whose effect you wish to remove from the outcome variable before consideration of others.) These models were used to identify outliers: local authorities which, having controlled for variation that might be explained by the deprivation models, have either higher or lower conception and abortion rates than would be expected. In order to determine which authorities were outliers, we calculated the studentised deleted residual (sometimes also called the externally standardised residual) for each case. These are distributed as a $t$ with $n-1$ degrees of freedom (df). We calculated the probability associated with each residual, and used 0.01 as a cut-off to determine which authorities had significant residuals.

Most previous research on area variation in conceptions and abortions has relied on census variables or indices derived from the census. The index of deprivation used in this analysis is the Department of Environment, Transport and Regions (DETR) deprivation index. ${ }^{12}$ This index is made up of a number of domains.

Income: The income domain is represented by the percentage of people in the area dependent on one or more key means-tested benefits: Income Support, Job Seekers Allowance, Family Credit, Disability Working Allowance or estimated pensioners on Council Tax Benefit.

Child poverty index: This is a supplementary index and is the proportion of children under 16 years in each area living in families receiving the above means-tested benefits.

Employment: The employment domain is represented by the proportion of those who are economically active or incapacitated in an area and who want to work but are unable to do so due to unemployment, sickness or disability. Obviously, lack of employment may lead to income deprivation but these are treated as separate types of deprivation.

Health deprivation and disability: This domain presents those whose quality of life is impaired by either poor health or disability, including premature death, which is the ultimate manifestation of this. The indices used in this domain are: mortality rates for men and women aged under 65 years, numbers receiving Attendance Allowance or Disability Living Allowance, working-age people on Incapacity Benefit or Severe Disablement Allowance, age/sex standardised ratio of limiting long-term illness, and the proportion of low birth weight births.

Education, skills and training: This domain is predominantly measured by lack of qualifications amongst adults and children of different ages in a local area. The indicators used in this domain are: working-age adults with no qualifications (district level modelled down to ward level), children aged 16 years and over who are not in fulltime education, the proportion of 17-19-year-olds who have not applied for higher education, Key Stage 2 results at primary school level (converted to ward data), primary school children with English as an additional language, and absenteeism at primary level (all absences).

Housing: This domain identified people living in homeless households in temporary accommodation, overcrowded households and poor private sector housing.

Geographical access to services: The indices used in this domain are geographical access to: post office, food shops, a GP and primary school. Access for the first three indicators is estimated for those people in an area with low incomes (on benefits) as they are more likely to be experiencing the 
Table 1 Correlation matrix of the variables in the analysis

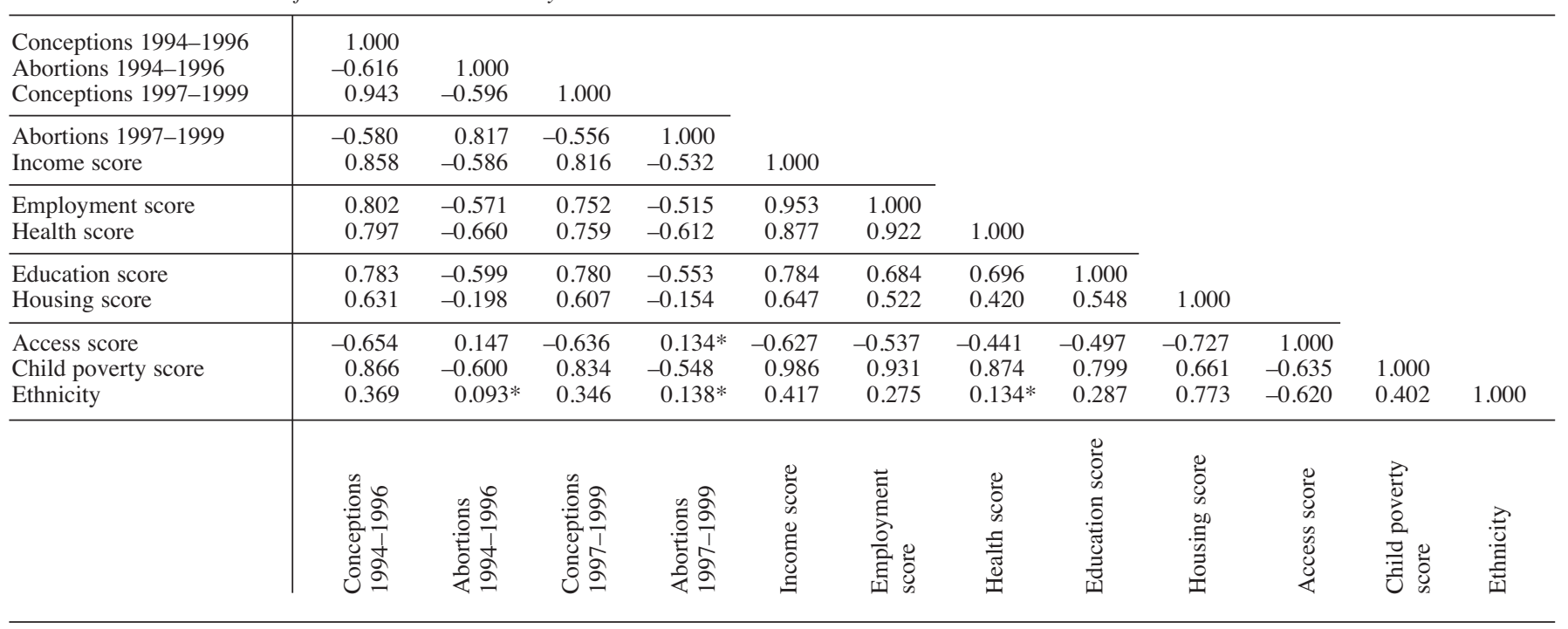

All correlations $p<0.01$, except $* p<0.05$.

disadvantage of lack of access to services more acutely than those on higher incomes, who are more able to afford public or private transport. The fourth indicator, access to primary schools, was measured for 5-8-year-olds.

The indicators were chosen to represent the domain on the grounds that they are statistically robust, up to date, available at small area level for the whole of England and they directly measure a major aspect of the dimension of deprivation. For all domains, the higher the score, the more deprived the local authority.

Ethnicity: One characteristic not included as a variable in the DETR deprivation index is ethnicity. The ethnicity variable in the model has been derived from the 1991 census (obtained from Haskey and Scott) ${ }^{13}$. Since 1991, some local authority boundaries have changed. When the local authority no longer exists, the figure for the closest corresponding geographical area has, where possible, been given. The variable is the percentage of the local authority district population who are ethnic minority; the higher the score, the higher the concentration of ethnic minorities.

\section{Results}

We found a moderate negative correlation $(r=-0.556$; Table 1) between the conception rate (1997-1999) and the abortion rate (1997-1999) in local authorities in England. This confirms previous research ${ }^{7}$ that found the higher the conception rate, the lower the proportion of conceptions aborted. This suggests that deprivation may be associated with both conceptions and abortions. Alternatively it may be that in areas where teenage pregnancy is more common, there may be less pressure to end it with abortion.

Comparing the correlation in conception rates and the abortion rates for the different time periods shows that the correlation for abortion is significantly lower than the correlation for conception (abortion, $r=0.817$; conception, $r=0.943 ;$ significance of difference $<0.001)$. This indicates that the abortion rate is less stable than the conception rate, and hence will be less likely to be explained by deprivation factors than the conception rate.

\section{Conceptions}

There is a clear and statistically significant relationship between the conception rate and each of the deprivation domains for both time periods (Table 1). The areas with higher levels of deprivation all tend to have higher conception rates. The exception is that areas with poor geographical access to services tend to have lower conception rates. This result is likely to be because of an association between lack of access to services and rurality, and rural areas have lower conceptions not because they have poor access but because of other factors associated with rural areas. Areas with high proportions of ethnic minorities tend to have higher rates of teenage conceptions.

\section{Abortions}

There is a negative correlation between the percentage of conceptions that end in abortion and the deprivation indicators; that is, the more deprived the area the lower the abortion rate. Again, areas with poor geographical access to services are an exception and have higher abortion rates. Also, areas with a high proportion of ethnic minorities tend to have higher abortion rates.

Table 2 shows models resulting from a multiple regression to explain the variation in the teenage conception and abortion rates for the two time periods. The proportion of variance explained for conceptions in the two time periods is higher than for abortions, as would be expected from the examination of the stability of the estimates.

The models for conceptions are similar with the health, education and access score significant for both time periods. The models for abortions are also similar with health, ethnicity and employment scores significant in both time periods and access score significant in the earlier period. Interpretation of the parameter estimates from the regression analyses can be challenging because of suppressor effects caused by collinearity. For example, in the abortion models the coefficients on employment deprivation are positive despite their negative correlation with abortions in Table 1. This effect is caused by the correlation between employment and other deprivation variables in the model. In interpreting these results we should remember that the standardised regression estimates estimate the effect of each predictor, whilst holding all others constant.

Table 3 shows the outlying local authorities that have conception and abortion rates that are significantly different from those predicted by the model. A negative residual indicates that the rate for the authority is lower than would be predicted by the model. A positive residual indicates that the authority is higher than would be predicted by the model. The residuals are distributed as $t$, with $n-1 \mathrm{df}$, and so the probabilities are also listed in the table. Residuals with a probability less than 0.01 are listed. (NB. We have chosen to use 0.01 rather than 0.05 because of the relatively large sample size - if we were to use 0.05 
ARTICLE

Table 2 Regression of conception and abortion onto deprivation measures

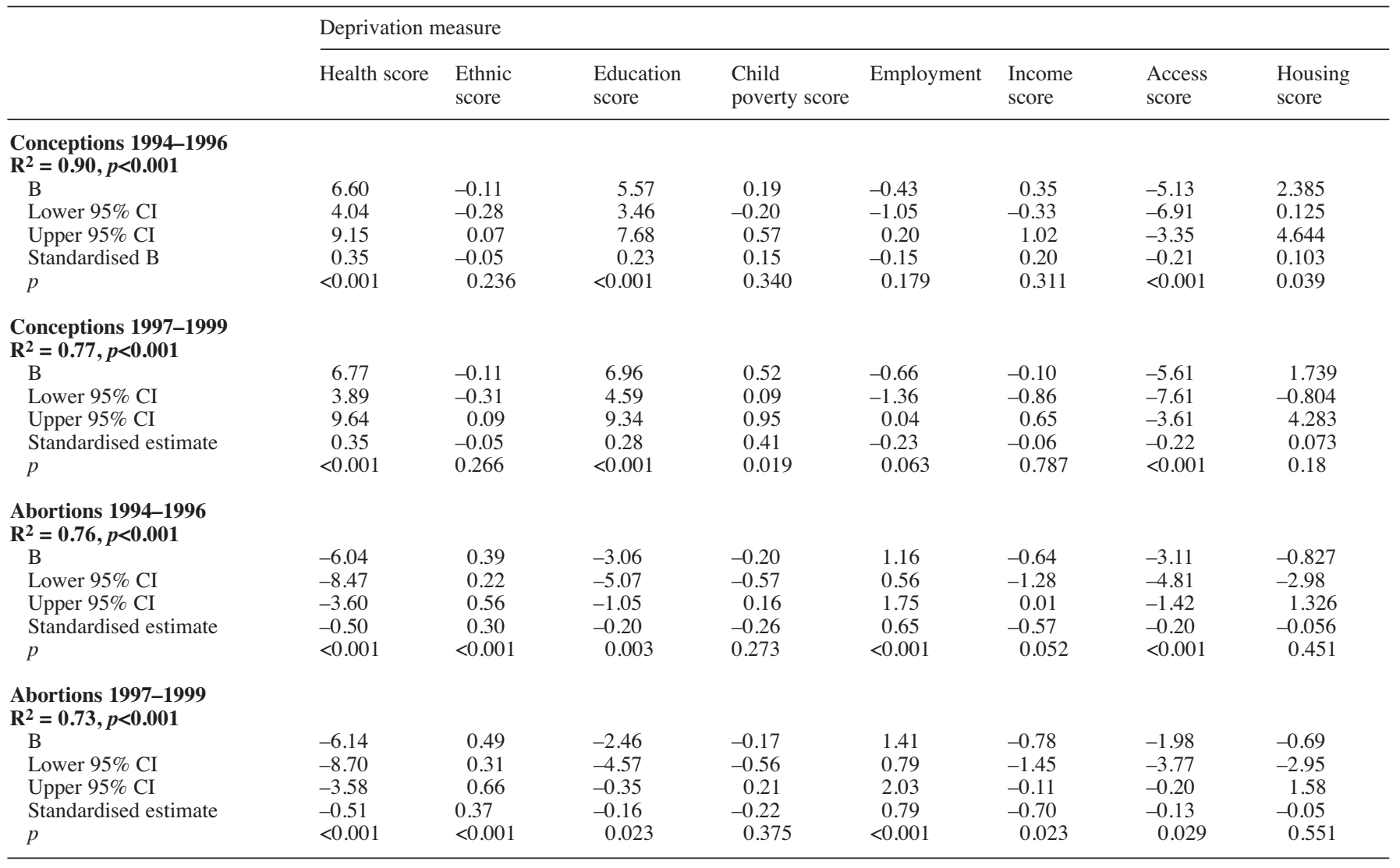

B, slope parameter; CI, confidence interval.

we would expect 1 in 20 authorities to be identified as statistically significant residuals when, in fact, there was only random variation present.)

So in 1994-1996, Lambeth, Southwark, Crewe and Nantwich and Swindon all had higher conception rates than their deprivation levels would have predicted and Tower Hamlets and Knowsley had lower conception rates than expected given their levels of deprivation. In the later period, the same local authorities had higher conception rates except Swindon fell out and Lewisham, Hartlepool and Corby were added. Only Tower Hamlets had a lower conception rate than predicted. On abortion in the earlier period, Ryedale, East Dorset, Rochford and South Hams had higher proportions of conceptions aborted than predicted by their deprivation and Kennet had a lower proportion aborted. In the later period, West Somerset was the only outlier with a much higher proportion of abortions than predicted.

Tables 4 and 5 show the model for a hierarchical regression to test whether the rate in the earlier period predicts the change in conception rates in the later period. The first model, which controls for the earlier time only, is our baseline and shows that $89 \%$ of the variation in conception rate in the later period is predicted by the conception rate in the earlier period. The second model, which controls for the earlier time and the deprivation model, predicts only an additional $1 \%$ of the $11 \%$ unexplained by our first model. This suggests that factors other than deprivation, such as policy, explain the remaining $10 \%$ change in the conception rate.

The results are very similar for the abortion data. Abortion rates in the earlier period explain $67 \%$ of the variation. The addition of the deprivation measures explains $2 \%$ of the unexplained variance in the abortion rate, again suggesting that factors other than deprivation explain the remaining $31 \%$ of the change in the abortion rate.
Table 3 Studentised deleted residuals and Bonferroni correct probability

\begin{tabular}{|c|c|c|c|c|}
\hline & $\begin{array}{l}\text { Studentised } \\
\text { residual }\end{array}$ & $p$ & $\begin{array}{l}\text { Actual } \\
\text { rate }\end{array}$ & $\begin{array}{l}\text { Predicted } \\
\text { rate }\end{array}$ \\
\hline \multicolumn{5}{|l|}{ Conceptions 1994-1996 } \\
\hline \multicolumn{5}{|l|}{ Positive } \\
\hline Lambeth & 4.78 & $<0.001$ & 86 & 57.6 \\
\hline Southwark & 4.20 & $<0.001$ & 88 & 62.7 \\
\hline Crewe and Nantwich & 3.25 & 0.002 & 54 & 33.9 \\
\hline Swindon & 2.87 & 0.007 & 59 & 41.2 \\
\hline \multicolumn{5}{|l|}{ Negative } \\
\hline Knowsley & -3.01 & 0.004 & 52 & 69.7 \\
\hline Tower Hamlets & -3.79 & $<0.001$ & 56 & 77.9 \\
\hline \multicolumn{5}{|l|}{ Conceptions 1997-1999 } \\
\hline \multicolumn{5}{|l|}{ Positive } \\
\hline Lambeth & 4.78 & 0.000 & 85 & 59.4 \\
\hline Southwark & 4.20 & 0.001 & 86 & 63.0 \\
\hline Crewe and Nantwich & 3.25 & 0.006 & 57 & 36.5 \\
\hline Wear Valley & 2.41 & 0.009 & 74 & 54.9 \\
\hline Lewisham & 1.91 & 0.004 & 79 & 57.7 \\
\hline Hartlepool & 1.87 & 0.007 & 77 & 57.2 \\
\hline Corby & 1.19 & 0.001 & 75 & 50.0 \\
\hline \multicolumn{5}{|l|}{ Negative } \\
\hline Tower Hamlets & -3.79 & $<0.0001$ & 52 & 79 \\
\hline \multicolumn{5}{|l|}{ Abortions 1994-1996 } \\
\hline \multicolumn{5}{|l|}{ Positive } \\
\hline Ryedale & 3.92 & $<0.0001$ & 67 & 44.4 \\
\hline East Dorset & 3.12 & 0.003 & 66 & 47.7 \\
\hline Rochford & 2.87 & 0.007 & 65 & 48.1 \\
\hline South Hams & 2.73 & 0.010 & 59 & 42.9 \\
\hline \multicolumn{5}{|l|}{ Negative } \\
\hline Kennet & -3.05 & 0.004 & 31 & 49.0 \\
\hline \multicolumn{5}{|l|}{ Abortions 1997-1999 } \\
\hline \multicolumn{5}{|l|}{ Positive } \\
\hline West Somerset & 4.37 & $<0.001$ & 66 & 39.8 \\
\hline \multicolumn{5}{|l|}{ Negative } \\
\hline None with $p \leq 0.01$ & & & & \\
\hline
\end{tabular}


Table 4 Hierarchical regression to test predictors of change in conception and abortion rates ${ }^{\mathrm{a}}$

\begin{tabular}{lllll}
\hline & Model & $\mathrm{R}^{2}$ & $\Delta \mathrm{R}^{2}$ & $p \Delta \mathrm{R}^{2}$ \\
\hline Conceptions & 1 & 0.89 & 0.89 & $<0.001$ \\
Abortion & 2 & 0.90 & 0.01 & $<0.001$ \\
& 2 & 0.67 & 0.67 & $<0.001$ \\
& 2 & 0.69 & 0.02 & $<0.001$
\end{tabular}

a Model 1 contains the 1994-1996 rate only, Model 2 contains the 1994-1996 rate, plus the deprivation predictors.

Table 6 shows the residuals from this analysis of change in conception and abortion rates. Boston, Corby and Runnymede have increased their conception rates significantly more than expected and Purbeck, Redditch and Manchester have reduced their conception rate more than expected. Only West Somerset has had a significant increase in the proportion of conceptions that end in abortion.

\section{Discussion}

More than three quarters of area variation in the teenage conception rate and about three quarters of the variation in the abortion rate can be explained by models of deprivation and ethnicity. Most of the areas identified as outliers would not have been those selected if no attempt had been made to control for deprivation. Neither would we have identified the same local authorities experiencing sharp changes in their teenage conception or abortion rate if we had not first controlled for deprivation. Local authorities comparing their performance in relation to the teenage pregnancy strategy would be well advised to make comparisons after controlling for deprivation - they may find that they are doing much better or much worse than they should be given their deprivation. To take an example from our region in the ranking of conception rates, Kingston upon Hull comes 342 and Harrogate comes 52 out of 352 local authorities in England. In 1997-1999, after controlling for deprivation, Kingston upon Hull drops to 321 and Harrogate rises to 213. (NB.A full list of local authorities with their actual and predicted conception and abortion rates is available at http://www.york.ac.uk/mst/spru/research/summs/teens.html.)

Clearly other factors not included in our models are also contributing to variation, and this is more the case in the later period. They may be socioeconomic factors not covered by the deprivation index and the ethnicity variable. For example, religious beliefs or concentrations of young men in

Table 5 Parameter estimates predicting change in conception and abortion rates

\begin{tabular}{lrrrrr}
\hline & & $\begin{array}{l}\text { Lower } \\
\text { 95\% CI }\end{array}$ & $\begin{array}{l}\text { Upper } \\
\text { 95\% CI }\end{array}$ & $\begin{array}{l}\text { Standard- } \\
\text { ised } \\
\text { estimate }\end{array}$ & $p$ \\
& $\mathrm{~B}$ & & & & \\
\hline Conceptions 1997-1999 & & & & & \\
Conceptions 1994-1996 & 0.84 & 0.76 & 0.92 & 0.82 & $<0.001$ \\
Income score & -0.40 & -0.90 & 0.11 & -0.22 & 0.125 \\
Employment score & -0.31 & -0.77 & 0.16 & -0.11 & 0.199 \\
Health score & 1.23 & -0.76 & 3.22 & 0.06 & 0.226 \\
Education score & 2.29 & 0.64 & 3.93 & 0.09 & 0.007 \\
Housing score & -0.26 & -1.97 & 1.45 & -0.01 & 0.763 \\
Access score & -1.30 & -2.70 & 0.09 & -0.05 & 0.068 \\
Child poverty score & 0.36 & 0.07 & 0.65 & 0.29 & 0.014 \\
Ethnicity & -0.02 & -0.16 & 0.11 & -0.01 & 0.731 \\
Abortions 1997-1999 & & & & & \\
Abortions 1994-1996 & 0.63 & 0.54 & 0.72 & 0.63 & 0.000 \\
Income score & -0.38 & -0.92 & 0.16 & -0.34 & 0.170 \\
Employment score & 0.68 & 0.17 & 1.19 & 0.38 & 0.009 \\
Health score & -2.33 & -4.45 & -0.22 & -0.20 & 0.031 \\
Education score & -0.53 & -2.24 & 1.19 & -0.03 & 0.547 \\
Housing score & -0.17 & -1.98 & 1.65 & -0.01 & 0.858 \\
Access score & -0.02 & -1.48 & 1.43 & 0.00 & 0.976 \\
Child poverty score & -0.04 & -0.35 & 0.26 & -0.06 & 0.775 \\
Ethnicity & 0.24 & 0.09 & 0.38 & 0.18 & 0.002 \\
\hline
\end{tabular}

B, slope parameter; CI, confidence interval.
Table 6 Studentised deleted residuals and Bonferroni corrected probability for 1997-1999 rates regressed on 1994-1996 rates and deprivation scores

\begin{tabular}{|c|c|c|c|c|}
\hline & $\begin{array}{l}\text { Studentised } \\
\text { residual }\end{array}$ & $p$ & $\begin{array}{l}\text { Actual } \\
\text { rate }\end{array}$ & $\begin{array}{l}\text { Predicted } \\
\text { rate }\end{array}$ \\
\hline \multicolumn{5}{|l|}{ Conceptions } \\
\hline \multicolumn{5}{|l|}{ Positive residuals } \\
\hline Boston & 4.48 & $<0.001$ & 66 & 45.7 \\
\hline Corby & 4.14 & $<0.001$ & 75 & 56.2 \\
\hline Runnymede & 3.05 & 0.004 & 43 & 28.9 \\
\hline \multicolumn{5}{|l|}{ Negative residuals } \\
\hline Purbeck & -2.90 & 0.006 & 26 & 39.5 \\
\hline Redditch & -3.52 & 0.001 & 41 & 57.2 \\
\hline Manchester & -3.60 & 0.001 & 58 & 74.4 \\
\hline \multicolumn{5}{|l|}{ Abortions } \\
\hline West Somerset & 6.85 & $<0.001$ & 66 & 34.4 \\
\hline \multicolumn{5}{|l|}{ Negative residuals } \\
\hline None with $p \leq 0.01$ & & & & \\
\hline
\end{tabular}

army camps are the kind of factors that might be expected to contribute. Having taken account of socioeconomic factors, the most likely explanations are to be found in variations in services. The residual variation in the conception rate may be a function of the effectiveness of sex education and/or the accessibility of contraceptive advice and services. The variation in the abortion rate may be a function of the accessibility of abortion services at a local level.

Clearly more detailed research on the ground is required to obtain a better understanding of how and why local areas manage to buck the characteristics of their own population. However, the kind of analysis presented in this article can be a powerful tool for identifying the areas that look as if they are doing things well in relation to reducing teenage conceptions and births - given their circumstances.

Acknowledgement

Rebecca Parrish extracted the ethnicity data and added it to the database.

Statements on funding and competing interests

Funding. None identified.

Competing interests. None identified.

References

Bradshaw N, Bradshaw J, Burrows R. Area variations in the prevalence of lone parent families in England and Wales: a research note. Regional Studies 1996; 30: 811-815.

2 Webster D. Lone parenthood: two views and their consequences. In: Anderson I, Sim D (eds), Social Exclusion and Housing: Context and Challenges. Coventry, UK: Chartered Institute of Housing, 2000.

3 Smith T. Influence of socio-economic factors on attaining targets for reducing teenage pregnancies. BMJ 1993; 306: 1232-1235.

4 Wood R. Subnational variations in conceptions. Popul Trends 1996; 84: $21-27$.

5 Sloggett A, Joshi H. Deprivation indicators as predictors of life events, 1981-1992 based on the ONS Longitudinal Study. J Epidemiol Community Health 1998; 52: 228-233.

6 Clements S, Stone N, Diamond I, Ingham R. Modelling the spatial distribution of teenage conception rates within Wessex. Br J Fam Plann 1998; 24: 61-71.

7 Teenage Pregnancy. London, UK: Social Exclusion Unit, 1999. http://www.socialexclusionunit.gov.uk/publications/asp?id=69.

8 Griffiths C, Kirby L. Geographic variations in conceptions to women aged under 18 in Great Britain during the 1990s. Popul Trends 2000; 102: $13-23$.

9 Ingham R, Clements S, Gillibrand R. Factors effecting changes in rates of teenage conceptions. http://www.socstats.soton.ac.uk/cshr/ changes.pdf.

10 Lee E, Clements S, Ingham R, Stone N. A Matter of Choice? Explaining National Variations in Teenage Abortion and Motherhood, York, UK: Joseph Rowntree Foundation, 2004.

11 Office for National Statistics. Abortion Statistics Annual Reference Volume. Series AB No. 28. London, UK: The Stationery Office, 2001.

12 Department of Environment, Transport and Regions (DETR). Indices of Deprivation. Regeneration Research Summary No. 3. London, UK: DETR, 2000.

13 Haskey J, Scott A. More reliable minority ethnic population estimates and proportion for local areas: which areas to select and other choices to be made - an exploratory analysis. Popul Trends 2001; 105: 16-36. 